\title{
Electroejaculation, semen characteristics and semen preservation of the brindled gnu
}

\author{
P. F. Watson* \\ Wellcome Institute of Comparative Physiology, The Zoological Society of London, \\ Regent's Park, London NWI 4RY, U.K.
}

Interest in the application of the techniques of artificial breeding to non-domesticated mammals has been stimulated in recent years by the failure of some species to breed in captivity and by the decreasing availability of animals from the wild. Several authors have drawn attention to the need to develop techniques suitable for exotic animals (Jones, 1971 ; Francoeur, 1972; Rowlands, 1965, 1974; Warner, Martin \& Keeling, 1974), but as yet very few species have been studied.

A brindled gnu (Connochaetes taurinus) at The Zoological Society of London was sedated with Xylazine (Rompun, Bayer U.K. Ltd) and semen was collected by electroejaculation using finger ring electrodes and a sine wave stimulator (Watson \& Hime, 1976). Stimulation for periods of $5 \mathrm{sec}$ with 5 -sec rest periods was commenced with a frequency of $10-15 \mathrm{~Hz}$ and a peak voltage of $7 \cdot 5 \mathrm{~V}$ (Text-fig. 1a). After $30 \mathrm{sec}$ the frequency was increased to $30 \mathrm{~Hz}$ and the peak voltage to $15 \mathrm{~V}$ (Text-fig. $1 \mathrm{~b}$ ). The penis extruded about $9-11 \mathrm{~cm}$ before a forceful ejaculation and semen was produced during several successive 5-sec stimulation periods.

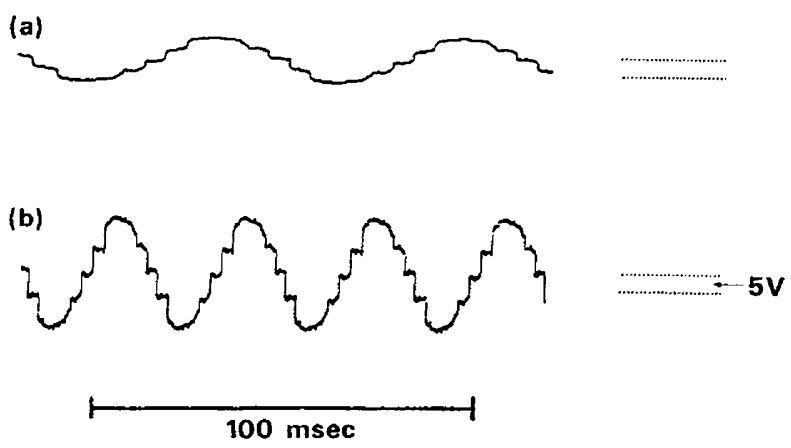

Text-fig. 1. Oscilloscope display of the output of the stimulator used for electroejaculation of the brindled gnu. (a) Low output used to commence stimulation; (b) maximum output which evoked ejaculation.

The semen had a milky consistency and showed strong wave motion typical of bull semen. The concentration of spermatozoa in the ejaculate was calculated from haemocytometer counts of diluted semen. The percentage of motile spermatozoa was estimated immediately after dilution of semen at $30^{\circ} \mathrm{C}$ in buffered citrate solution. Estimates of the percentage of live spermatozoa were made using the eosin-nigrosin method of Hancock (1951). Thecharacteristics of the ejaculates collected on 2 occasions were:

Volume (ml)

Sperm concentration $\left(\times 10^{6} / \mathrm{ml}\right)$

Motility (\%)

$\%$ Unstained spermatozoa (eosin-nigrosin)

$\begin{array}{cc}\text { Ejaculate 1 } & \text { Ejaculate } 2 \\ 10 \cdot 5 & 12 \cdot 0 \\ 184 & 520 \\ 50 & 70 \\ 82 & 89 \cdot 5\end{array}$

* Present address: Department of Physiology, The Royal Veterinary College, Royal College Street, London NW1 OTU, U.K. 
The lower values for the first ejaculate were probably due to ageing of the spermatozoa, since the animal had not mated for several weeks before electroejaculation.

Gnu spermatozoa resemble those of domestic ungulates in having a bilaterally flattened paddleshaped head. The midpiece inserts axially into the base of the head. Planimetry of 200 gnu spermatozoa in fixed smears lightly stained with Giemsa (Watson, 1975), at a magnification of $\times 1250$ for the sperm heads and $\times 500$ for midpieces and overall measurements, gave the following results (mean \pm S.E.M.): head length $6.86 \pm 0.03 \mu \mathrm{m}$, breadth of head at widest point, $4.58 \pm 0.02 \mu \mathrm{m}$, length of midpiece $11.13 \pm 0.08 \mu \mathrm{m}$, overall length of spermatozoon, $66.66 \pm 0.24 \mu \mathrm{m}$. The head of the gnu spermatozoon is smaller than that of bull or ram spermatozoa (Bishop \& Walton, 1960; Van Duijn \& Van Voorst, 1971), even allowing for alterations in size caused by processing (Van Duijn, 1960; Van Duijn \& Van Voorst, 1971). These measurements are consistently greater than those given in the only other report of gnu spermatozoa (Morgenthal, 1967), but Morgenthal measured epididymal spermatozoa, which in the rabbit are known to have a smaller projected head area than ejaculated spermatozoa (Paufler \& Foote, 1968), and his dimensions of spermatozoa of domestic ungulates are also smaller than those generally given.

Two experiments were performed to examine some of the diluent requirements for gnu spermatozoa and to investigate the response to freezing and thawing. Semen was diluted 5 -fold at $30^{\circ} \mathrm{C}$, cooled to $5^{\circ} \mathrm{C}$ over $3 \mathrm{hr}$ and then further diluted with a glycerol-containing portion of diluent. The final dilution was 10 -fold and the glycerol concentration was $7 \cdot 5 \%(\mathrm{v} / \mathrm{v})$. Diluted semen was sealed in $0.5 \mathrm{ml}$ Cassou straws and frozen $4 \mathrm{~cm}$ over the surface of liquid nitrogen. Motility, percentage motile and acrosome scores were made on thawed semen as previously described (Watson, 1975; Watson \& Martin, 1975). Analyses of variance were calculated for each of these parameters.

Table 1. The effects of freezing and thawing brindled gnu semen in buffered egg yolkglucose diluent (mean scores of 3 straws/treatment)

\begin{tabular}{ccccc}
\hline $\begin{array}{c}\text { Egg yolk } \\
\text { conc. (\%) }\end{array}$ & $\begin{array}{c}\text { Equilibration } \\
\text { time at } \\
5^{\circ} \mathrm{C}(\mathrm{hr})\end{array}$ & $\begin{array}{c}\text { Motility } \\
\text { (scale 0-4) }\end{array}$ & $\begin{array}{c}\% \\
\text { motile } \\
\text { sperm. }\end{array}$ & $\begin{array}{c}\text { Acrosome } \\
\text { damage } \\
\text { (scale 0-3) }\end{array}$ \\
\hline 10 & 2 & 1.94 & 25.1 & 1.61 \\
20 & 18 & 1.79 & 32.9 & $1 \cdot 15$ \\
& 2 & 1.53 & 18.3 & 1.15 \\
& 18 & 1.24 & 19.4 & 0.98 \\
\hline
\end{tabular}

In Exp. 1 the effects of 10 or $20 \%$ egg yolk (v/v) in a glucose-phosphate diluent (Watson \& Martin, 1975) were examined, and equilibration periods of $2 \mathrm{hr}$ and $18 \mathrm{hr}$ at $5^{\circ} \mathrm{C}$ after the addition of glycerol were compared. The results after thawing (Table 1) indicated that $10 \%$ egg yolk was preferable to $20 \%(P<0.05)$, and equilibration for $18 \mathrm{hr}$ gave a slightly, but not significantly, better revival with $10 \%$ egg yolk. Least acrosome damage occurred with the higher egg yolk level $(P<0.01)$ and the longer equilibration period $(P<0.01)$. The interaction term was also significant, indicating that the detrimental effect of a shorter equilibration was greater at the lower egg yolk level $(P<0.05)$.

In Exp. 2, a citrate diluent (Martin \& Emmens, 1961) was used since, in a preliminary incubation experiment, gnu spermatozoa survived longer in an egg yolk-citrate diluent than in an egg yolk-glucose-phosphate diluent. The spermatozoa were equilibrated for $4 \mathrm{hr}$ before storage for 6 months in liquid nitrogen. After thawing the spermatozoa were incubated for 0,2 or $4 \mathrm{hr}$ at $37^{\circ} \mathrm{C}$ (Table 2). A 4-hr incubation significantly lowered motility and the \% of motile spermatozoa $(P<0.001)$, but there were no significant changes in acrosomal morphology. The lowest egg yolk concentration supported the spermatozoa better than the higher concentrations (motility score, $P<0.05 ; \%$ motile score, $P<0.01$ ). The interaction of 'egg yolk concentration $\times$ incubation time' was significant $(P<0.05)$ for motility and \% motile scores, reflecting the fact that the decline in sperm viability from 2 to $4 \mathrm{hr}$ of incubation in the $25 \% \mathrm{egg}$ yolk diluent was not as great as in the lower egg yolk concentrations. 


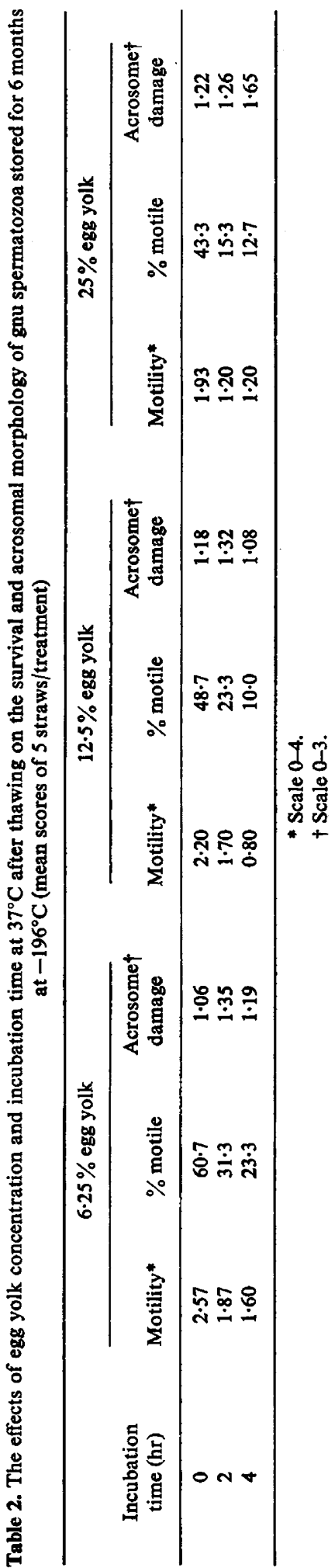


The slow development of the application of artificial insemination to non-domesticated animals is partly due to the lack of information on techniques for semen collection and preservation. Although limited to a single animal, the present study shows that gnu semen can be satisfactorily preserved by freezing, as judged by laboratory tests commonly used for cattle semen.

I thank the veterinary and menagerie staff; Mr D. L. Stewart, Director, M.A.F.F. Cattle Breeding Centre, Shinfield, Reading, for the loan of the electroejaculation equipment; Dr Jennifer Plummer of the Royal Veterinary College for the oscilloscope recording; and Miss A. Johnson and Mr T. Dennett for help with the planimetry and laboratory work, which was supported by the Ford Foundation.

\section{References}

Bishop, M.W.H. \& Walton, A. (1960) Spermatogenesis and the structure of mammalian spermatozoa. In Marshall's Physiology of Reproduction, Vol. 1, Part 2, pp. 1-129. Longmans Green \& Co., London.

Francoeur, R.T. (1972) Artificial insemination for species in danger. Oryx 11, 364-366.

Hancock, J.L. (1951) A staining technique for the study of temperature shock in semen. Nature, Lond. 167, 323-324.

JONES, R.C. (1971) Uses of artificial insemination. Nature, Lond. 229, 534-537.

Martin, I.C.A. \& Emmens, C.W. (1961) Effects of time of equilibration and addition of fructose on the survival and fertility of bull spermatozoa deep frozen to $-79^{\circ}$ C. $J$. Reprod. Fert. 2, 404 410.

MorgenthaL, J. C. (1967) Notes on the spermatozoal morphology of some ungulates. J. S. Afr. vet. med. Ass. 38, 271-273.

Paufler, S. \& Foote, R.H. (1968) Nuclear size and Feulgen-DNA content of epididymal and ejaculated rabbit spermatozoa. Proc. 6th Int. Congr. Anim. Reprod. \& A. I., Paris 2, 1291-1293.
Rowlands, I.W. (1965) Artificial insemination of mammals in captivity. Int. Z. Yb. 5, 105-106.

RoWLANDS, I.W. (1974) Artificial insemination of mammals in captivity. Int. Z. Yb. 14, 230-233.

VAN Duisn, C. (1960) Mensuration of the heads of bull spermatozoa. Mikroskopie 14, 265-276.

VAN DuiJn, C. \& Van Voorst, C. (1971) Precision measurements of dimensions, refractive index and mass of bull spermatozoa in the living state. Mikroskopie 27, 142-167.

Warner, H., Martin, D.E. \& Keeling, M.E. (1974) Electroejaculation in the great apes. Annls biomed. Engin. 2, 419-432.

Watson, P.F. (1975) Use of a Giemsa stain to detect changes in the acrosomes of frozen ram spermatozoa. Vet. Rec. 97, 12-15.

WAtson, P.F. \& Hime, J.M. (1976) Semen collection from the brindled gnu (Connochaetes taurinus). Int. Z. Yb. 16 (in press).

Watson, P.F. \& MARTin, I.C.A. (1975) Effects of egg yolk, glycerol and the freezing rate on the viability and acrosomal structures of frozen ram spermatozoa. Aust. J. biol. Sci. 28, 153-159. 